\title{
MINLP Model and two-level Algorithm for the Simultaneous Synthesis of Heat Exchanger Networks and Utility Systems
}

\author{
Emanuele Martelli, ${ }^{\mathrm{a}}$ Alberto Mian, ${ }^{\mathrm{b}}$ François Maréchal ${ }^{\mathrm{b}}$ \\ ${ }^{a}$ Politecnico di Milano, Via Lambruschini 4, 20156 Milano, Italy \\ ${ }^{b}$ Ecole Politechnique Fédérale de Lausanne, Station 9, 1015 Lausanne, Switzerland
}

\begin{abstract}
This work proposes a novel approach for the simultaneous synthesis of Heat Exchanger Networks (HEN) and Utility Systems. Given a set of hot and cold process streams and a set of available utility systems (e.g., gas turbine, steam cycle, boiler, etc), the method determines the optimal selection of utility systems, their arrangement and design (including steam generator), and the heat exchanger network (between process-process as well as process-utility and utility-utility streams) rigorously considering the trade-off between efficiency and capital costs. The mathematical model is formulated as a Mixed Integer NonLinear Program (MINLP) and it combines the SYNHEAT superstructure for HENs with ad hoc models/superstructures for utility systems. The challenging MINLP is solved with a two-level algorithm using at the upper level the Variable Neighbourhood Search (VNS) algorithm to optimize the integer variables, and at the lower level the SQP algorithm to optimize the real variables. The algorithm is tested on problems with up to 15 streams (corresponding to 465 binary variables).
\end{abstract}

Keywords: HEN synthesis, utility systems, MINLP, VNS, steam cycle

\section{Introduction}

The optimal design of energy systems and chemical processes involves also the synthesis of the Heat Exchanger Network (HEN) as well as of the utility systems necessary to provide thermal, refrigeration and electric power to the process units. To the best of our knowledge, all the available synthesis techniques tackle the two problems separately by limiting the set of integration options between the HEN and the set of utility streams. For instance, the well-known sequential approach proposed in the works of (Papoulias \& Grossmann, 1983a), (Papoulias \& Grossmann, 1983b) and (Floudas, Ciric, \& Grossmann, 1986) has the following limitations.

1. HEN and utility systems (e.g., steam cycle) are designed sequentially.

2. As far as steam cycles are concerned, it is assumed that only evaporating/condensing steam can be integrated within the HEN to supply/remove heat from the process. For example, hot process streams cannot heat up boiler feedwater or superheat steam.

3. The matches of each utility stream can only be in parallel (it is considered one utility substream for each match which involves the given utility, as shown in Fig. 1A). This implies that the HEN superstructure excludes the series arrangement shown in Fig. 1B. Note that the parallel arrangement is possible only if the outlet temperature of cold/hot utility stream is lower/hotter than the inlet temperature of the hot/cold streams matched. This constraint does not allow to use cold utility streams with high outlet temperatures (e.g., feedwater of a steam cycle with outlet temperature of 300 
${ }^{\circ} \mathrm{C}$ ) or hot utility streams with low outlet temperatures (e.g., flue gases with outlet temperature of $60^{\circ} \mathrm{C}$ ) excluding potentially advantageous utility systems.
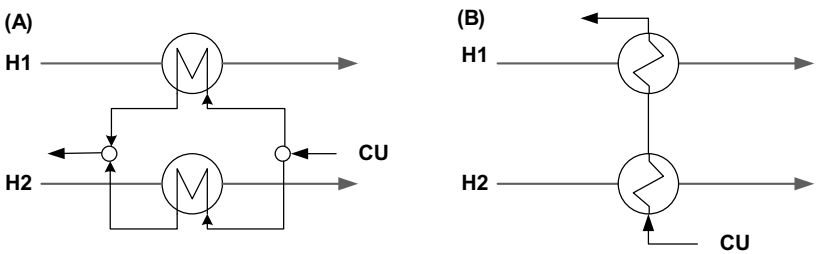

Figure 1. (A): cold utility stream with two matches in parallel (H1-CU and H2-CU). (B): cold utility stream with two matches in series.

Also simultaneous HEN synthesis techniques have limitations which make them not suitable for designing HENs optimally integrated with utility streams. For instance, the MINLP Synheat model of (Yee \& Grossmann, 1990) has the following limitations:

1. utility superstructures/models are not included for selection and optimization,

2. the optimization of the utility stream mass flow rates is not tackled because it would lead to nonlinear nonconvex constraints,

3. utility streams are not included in the HEN superstructure but placed at the hot and cold ends of the superstructure (thus, matches of each utility stream can be only in parallel, as shown in Figure 1A).

4. matches between streams of different utilities (e.g., boiler - steam cycle) are not possible.

In utility synthesis techniques the optimization of the process HEN is not dealt with. The utility system is optimized to provide the thermal, electric and refrigeration power required by the process (for fixed process HEN). Synthesis techniques for HENS with multiple utilities, like the one proposed by (Na, Jung, Park, \& Han, 2014), do not tackle the design problem of the utility systems (e.g., steam cycle and related boiler) and do not envisage the possibility for utility streams to have matches in series, as in Fig. 1B.

This work proposes a methodology and algorithm for the simultaneous synthesis of HENs and utility systems, which allows to (1) select among several available utility systems, (2) include complex superstructures of utility systems, (3) generate any possible match between process streams and utility streams, (4) optimize the design of the steam generator (arrangement and area of tube banks), (5) include design constraints on the HEN like "forbidden matches", "restricted matches" and "no stream splitting".

\section{Superstructure, mathematical model, and two-level algorithm}

The problem can be stated as below:

"Given a set of hot and cold process streams with given mass flow rates, inlet and outlet temperatures, and a set of available utility systems (e.g., cooling water, boiler, multiplelevel steam cycle, refrigeration cycle, heat pump, etc) with given structure or superstructure of possible configurations, the method simultaneously determines the optimal selection of utility systems, their design (arrangement of the steam generator as well as of other heat exchangers of the utility systems, turbine size, mass flow rates of each utility stream, etc), and the heat exchanger network between process-process as well as process-utility and utility-utility streams."

The proposed synthesis model combines the SYNHEAT temperature-stage HEN superstructure of (Yee \& Grossmann, 1990) with models and superstructures of utility systems, as shown in Fig. 2. Utility systems are divided in two categories, U-HEN and 
U-END. The streams of utilities in U-HEN can be fully integrated in the HEN, indeed they are dealt with as process streams (e.g., the gas turbine flue gases, the cooling air and the streams of the steam cycle in Fig. 2). Streams of utilities in U-END instead are not included in the HEN superstructure and they are placed at the hot/cold ends of the cold/hot streams (as done in (Yee \& Grossmann, 1990)). As a result, utility streams in U-END have limited matching options with other streams. However, they require a much lower number of binary and real variables compared to utility streams in U-HEN. A utility is included in U-END only if its streams have very hot/cold inlet and outlet temperatures compared to those of the cold/hot streams. In such a case, the optimal matching is likely to be at the hot/cold ends of the HEN superstructure. If this condition is not verified, it is advisable to include the utility in U-HEN so as not to exclude better matching options. It is worth noting that the set U-END may be empty if no utility can be reasonably classified as "hot/cold-end" utility, or a stream may not need a "hot/coldend" utility because its target temperature is variable (e.g., flue gases).

The optimization problems involves the following variables, objective function and constraints.

- Binary optimization variables: activation of utility system (U-END and U-HEN), activation of utility system options (only for utility with superstructure), activation of heat exchangers in the HEN (for process-process and process-utility streams in UHEN and utility-utility streams both in U-HEN), activation of end utility (in U-END) for each process stream as well as utility stream in U-HEN.

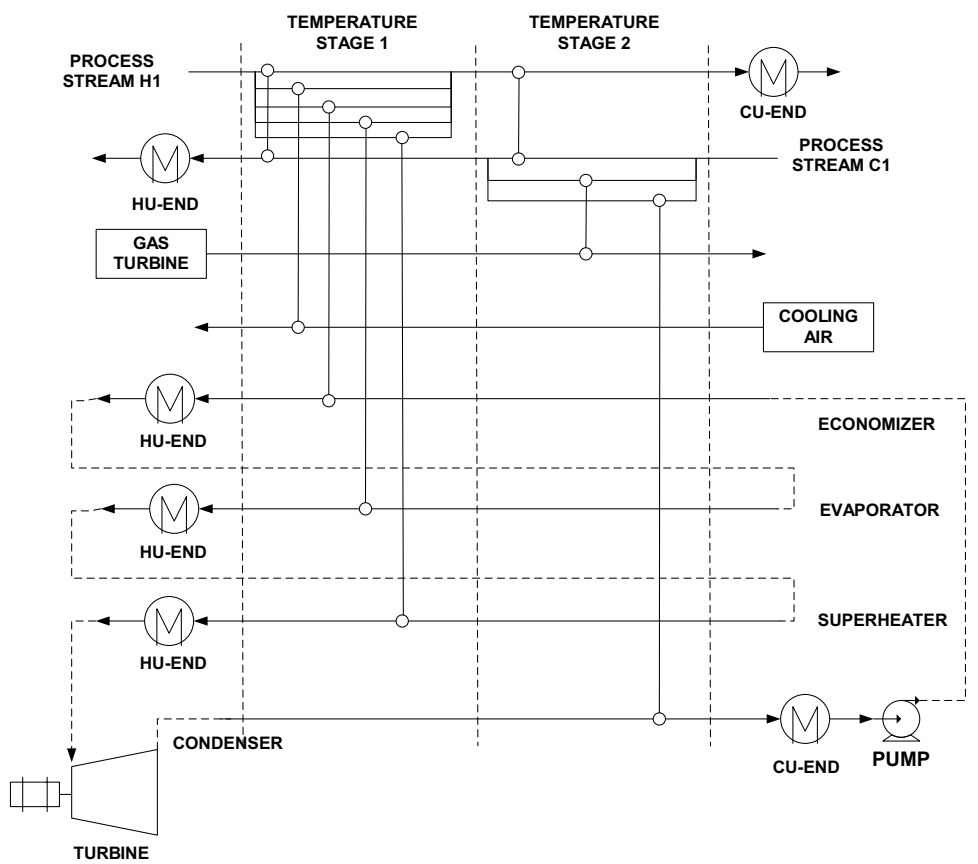

Figure 2. Superstructure of HEN and utility systems. CU-END and HU-END denote respectively "cold/hot-end" utilities.

- Real optimization variables: mass flow rates of utility streams, thermal power exchanged in each heat exchanger, stream temperatures at the inlet/exit of each heat exchanger. 
- Objective function: minimum total annual cost, sum of the utility capital cost (fixed activation cost + size depending cost), heat exchanger costs (fixed activation cost + area depending cost) and utility operating cost (energy consumption + other operating costs).

- Constraints: logical constraints to activate/deactivate utility systems and heat exchangers, energy balance equation of each stream, energy balance equation of each stream at each temperature stage, feasibility of stream temperatures in each match, model equations of each complex utility system (e.g., steam cycle), upper and lower bounds on each continuous variable.

It is worth noting that the energy balance equations contain bilinear terms (nonconvex), the products of flow rates and inlet/outlet temperatures of streams in U-HEN.

The challenging MINLP is tackled with a two-level algorithm: at the upper level the Variable Neighborhood Search (VNS) algorithm of (Egea et al., 2014) optimizes the binary variables (dealing with a balck-box integer problem), while at the lower level the SNOPT SQP algorithm optimizes the real variables. In order to minimize the variables and constraints of the lower-level NonLinear Program (NLP), the adaptive reformulation strategy of (Chen et al., 2008) is used. Given the combination of binary variables set by the VNS algorithm, it removes variables and constraints of the NLP.

\section{Test case}

The algorithm has been tested on several test cases including literature HEN synthesis problems (without utility optimization) and ad hoc problems comprising utility systems. Here we report the computational results for a test problem representative of integrated power plants (e.g., Integrated Gasification Combined Cycles) where the heat recovery steam generator (HRSG) must recover heat from multiple hot streams. Stream data are reported in Table 1. The heat exchangers have an activation cost of $3000 \$ / y$ and area cost of $150 \$ / \mathrm{m}^{2} \mathrm{y}$. The boiler has an activation cost $\left(\mathrm{C}_{\mathrm{A}}\right)$ of $40000 \$ / \mathrm{y}$ and energy + size-related cost $\left(\mathrm{C}_{\mathrm{P}}\right)$ of $200 \$ / \mathrm{kWy}$. For cooling water $\mathrm{C}_{\mathrm{A}}=4000 \$ / \mathrm{y}$ and $\mathrm{C}_{\mathrm{B}}=20$ $\$ / \mathrm{kWy}$, while for the steam cycle $\mathrm{C}_{\mathrm{A}}=1000000 \$ / \mathrm{y}$ and $\mathrm{C}_{\mathrm{B}}=-600000 \$ / \mathrm{kWy}$. A scale factor equal to 0.75 is considered for the area cost of the heat exchangers.

Table 1. Stream data of the test problem.

\begin{tabular}{lllll} 
Stream & $\mathrm{F}[\mathrm{kW} / \mathrm{K}]$ & Tin $\left[{ }^{\circ} \mathrm{C}\right]$ & Tout $\left[{ }^{\circ} \mathrm{C}\right]$ & $\mathrm{h}\left[\mathrm{kW} / \mathrm{Km}^{2}\right]$ \\
\hline H1 (process) & 200 & 600 & $>=60$ & 0.06 \\
H2 (process) & 40 & 900 & 250 & 0.04 \\
H3 (process) & 50 & 350 & 200 & 0.04 \\
C1 (process) & 20 & 100 & 250 & 0.5 \\
C2 (process) & 30 & 15 & 150 & 1.5 \\
BOILER (HU-END) & var & 1000 & 300 & 0.5 \\
COOLING WATER (CU-END) & var & 15 & 25 & 1.5 \\
\hline ECONOMIZER (CU-HEN) & var & 30 & 275 & 1 \\
EVAPORATOR (CU-HEN) & var & 275 & 275 & 10 \\
SUPERHEATER (CU-HEN) & var & 275 & 565 & 0.6 \\
CONDENSER (HU-HEN) & var & 30 & 30 & 2 \\
\hline
\end{tabular}

The optimization has been repeated for ten times with 60000 function evaluations of the VNS algorithm. The best solution is shown in Fig. 3 and its objective function value (total annual cost of the plant) is equal to $-19.4587 \mathrm{M} \$ / \mathrm{y}$ (being a negative value, it is a 
revenue). The average objective function of the solutions returned by the algorithm is equal to $-19.45259 \mathrm{M} \$ / \mathrm{y}$, which, being quite close to the best solution value, indicates a good reliability of the VNS algorithm. The CPU computational time of a run is about 800 seconds.

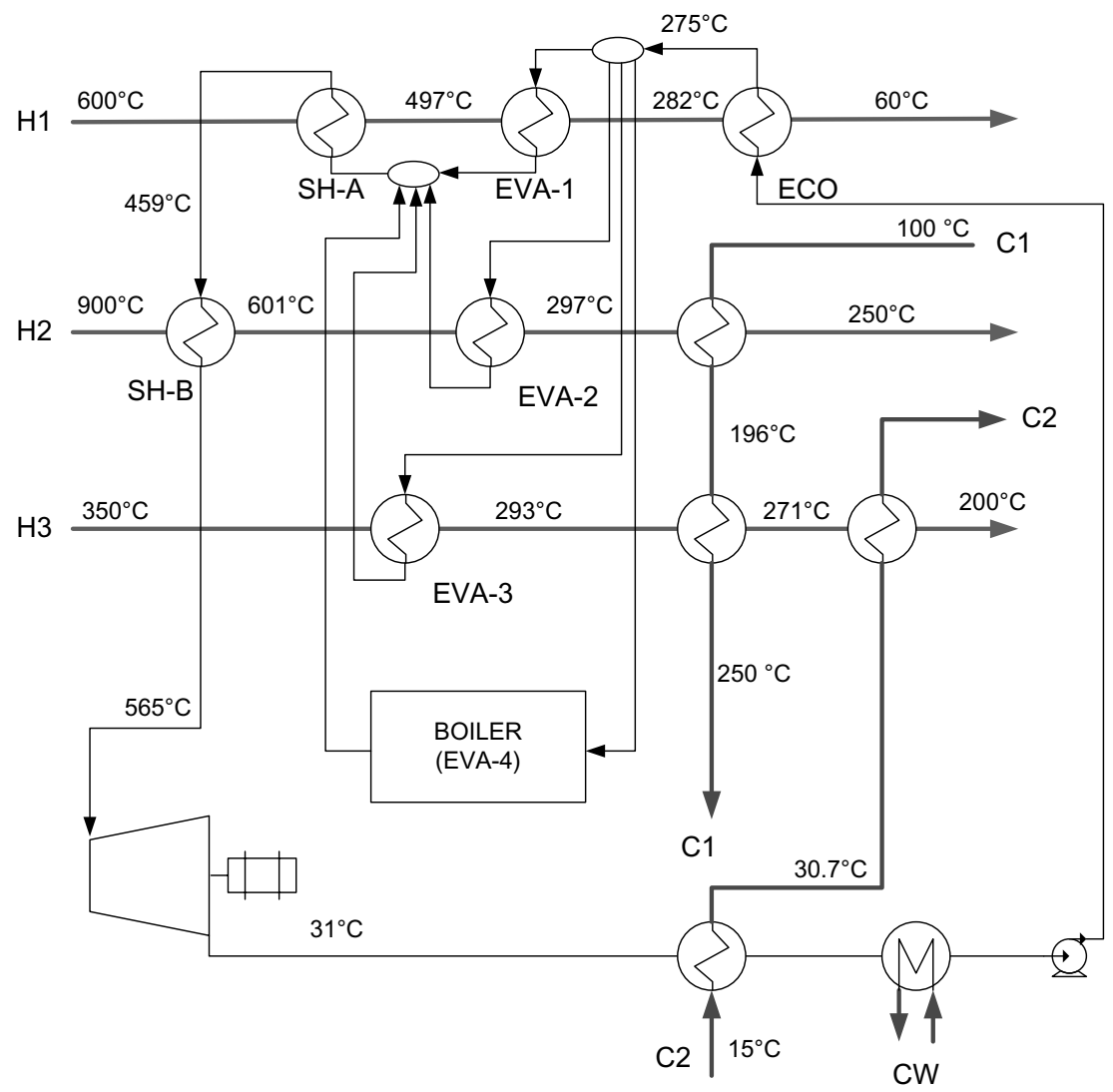

Figure 3. Best solution found by the two-stage algorithm

It is worth noting that the algorithm identifies a solution in which:

- heat exchangers of stream H1 are arranged as a conventional HRSG,

- steam superheating is split into two heat exchangers which are placed in series,

- steam evaporation is split into four heat exchangers (H1, H2, H3, boiler) connected in parallel.

- the steam cycle has been automatically arranged so as to perform cogeneration of power and heat, a particularly efficient thermodynamic solution, as it is heating up the cold stream $\mathrm{C} 2$ by means of the heat rejected by the condenser (at turbine outlet).

Such a solution with a so deep integration between the steam cycle and the process HEN cannot be found by other synthesis techniques. Also the layout of the HEN is really interesting as it combines energy efficiency and arrangement simplicity.

The algorithm has been tested also on literature problems with a larger number of streams, up to 15 , and up to 465 integer variables. Computational results indicate that the number of function evaluations of the VNS algorithm required to reach close-tooptimal solutions increases considerably. For instance, with 465 integer variables, 300000 function evaluations (corresponding to $10000 \mathrm{~s}$ CPU time) are not sufficient to 
find the optimal solution. However the returned solution has an objective function value only $3 \%$ suboptimal compared to the best-known solutions for the literature problem.

\section{Conclusions}

Compared to classic HEN synthesis methods, the proposed methodology returns improved HENs and utility system designs in which utility streams are fully integrated within the HEN and advantageous thermodynamic expedients, such as cogeneration, are exploited. The SQP algorithm is extremely efficient and, most important, finds the global optimum also for the problem formulations with variable utility flows (with nonlinear nonconvex constraints). The computational time and convergence rate (in terms of decrease rate of the objective function) of VNS strongly depends on the number of integer variables. However close-to-optimal solutions can be obtained also for problems with a large number of streams within a reasonable computational time (10000 s CPU time), and parallel-computing environment optimized for SQP algorithms, like that proposed by (Kang, Liu, Ren, \& Tang, 2014), may significantly decrease the computational time. Future works are aimed at including more complex utility superstructures and testing other optimization algorithms (e.g., branch-bound gradient-based MINLP methods).

\section{Acknowledgements}

The authors acknowledge the Swiss National Science Foundation (SNSF) for having supported this work by funding the visiting period of Ass. Prof. Martelli at EPFL (grant number IZK0Z2_157270).

\section{References}

X. Chen, Z. Li, J. Yang, , Z. Shao, 2008. Nested Tabu Search and Sequential Quadratic Programming Method, Combined with Adaptive Model Reformulation for Heat Exchanger Network Synthesis, Industrial \& Engineering Chemistry Research, 47, 2320-2330.

J.A. Egea, D. Henriques, T. Cokelaer, A. F. Villaverde, A. Macnamara, D. Danciu, J. Saezrodriguez, 2014, MEIGO : an open-source software suite based on metaheuristics for global optimization in systems biology and bioinformatics, BMC Bioinformatics, 15(136), 1-9.

C.A. Floudas, A. Ciric, I.E. Grossmann, 1986, Automatic synthesis of optimum heat exchanger network configurations, AIChE Journal, 32(2), 276-290.

L. Kang, Y. Liu, Y. Ren, Y. Tang, 2014, Optimal Design of Heat Exchanger Networks by Using SQP Algorithm Based on GPU Acceleration, Computer Aided Chemical Engineering, 33, 295-300.

J. Na, J. Jung, C. Park, C. Han, 2014, Simultaneous Optimization Models for Heat Exchanger Network Synthesis with Multiple Utilities : A New Strategy by Using Utility Sub-stage, Computer Aided Chemical Engineering, 33, 1675-1680.

S. Papoulias, I.E. Grossmann, 1983a, A structural optimization approach in process synthesis-I: utility systems, Computers \& Chemical Engineering, 7(6), 695-706.

S. Papoulias, I.E. Grossmann, 1983b, A structural optimization approach in process synthesis-II Heat Recovery Networks, Computers \& Chemical Engineering, 7(6), 707-721.

T. Yee, I.E. Grossmann, 1990, Simultaneous optimization models for heat integration-II. Heat exchanger network synthesis, Computers \& Chemical Engineering, 14(10), 1165-1184. 